Case Report:

\title{
Application of the Ecology of Human Performance in Cardiac Occupational Therapy: A Case Study
}

\author{
Zeinab Fathipour-Azar ${ }^{1 *}$ [D, Mahnaz Hejazi-Shirmard ${ }^{1}$ (i)
}

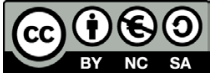

*This work has been published under CC BY-NC-SA 4.0 license.

Article info:

Received: 05 Jun 2018

Accepted: 10 Aug 2018

Available Online: 28 Nov 2019

Funding

This research did not receive any specific grant from funding agencies in the public, commercial, or not-forprofit sectors.

Conflict of interest

The authors declared no conflict of interest.

\section{A B STRACT}

The theories of occupational therapy always emphasize on the relationship between a person, his or her context, and occupations or tasks. Based on these theories, proper occupational performance results from appropriate interaction between these components. There is little evidence on the clinical practice of this theory in cardiac rehabilitation. So, this study aimed to investigate the implication of the Ecology of Human Performance (EHP) in a 50 years old man with cardiovascular disease. The participant was assessed and treated at home by an occupational therapist based on EHP principles. Results indicated that the intervention based on EHP was associated with improved performance and satisfaction of performance as well as independence in the activities of daily living. So, occupational therapists can use EHP to provide client-centered interventions and improve the occupational performance of clients with cardiovascular diseases. However, further studies with more methodological rigor are needed on this topic.

Keywords: Ecology of humane performance, Occupational therapy, Heart disease

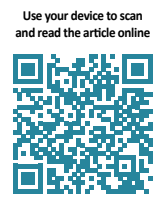

Cite this article as Fathipour-Azar Z, Hejazi-Shirmard M. Application of the Ecology of Human Performance in Cardiac Occupational Therapy: A Case Study. Function and Disability Journal. 2019; 2:183-188. http://dx.doi.org/10.32598/fdj.2.26.6

doi http://dx.doi.org/10.32598/fdj.2.26.6

* Corresponding Author:

\section{Zeinab Fathipour-Azar}

Address: Department of Occupational Therapy, School of Rehabilitation Sciences, Iran University of Medical Sciences,

Tehran, Iran.

Tel: +98 (901) 3892113

E-mail:fathipourz@yahoo.com
† What is "already known" in this topic:

There are limited evidences in using models and theories in occupational therapy.

What this article adds:

Using the Ecology of Human Performance Model shows positive results in the process of assessment and intervention of cardiac patients. 


\section{Introduction}

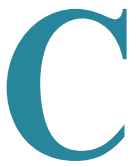

ardiovascular disease is one of the leading causes of death in low- and middle-income countries. It is also one of the main causes of disease burden in developing countries [1] According to the latest statistics announced by the World Health Organization, 33.7\% of mortality rate is due to cardiovascular diseases in the world and more than $80 \%$ of cardiovascular diseases occur in lowand middle- income countries [2]. In Iran, $41.3 \%$ of total deaths in 2005 were due to cardiovascular diseases and this rate is estimated to reach $44.8 \%$ in 2020 [3].

Cardiovascular diseases have negative impacts on executive function, attention, and memory [4]. They restrict participation in the Activities of Daily Living (ADL), work, leisure, sex, and roles in family life [5, 6] and consequently decrease the quality of life of the patients and their families [7].

Cardiac rehabilitation is a multidisciplinary intervention and mainly includes exercise training, education about cardiovascular risk reduction, behavior change, stress management, and psychological counseling $[8,9]$. Based on the evidence, cardiac rehabilitation can decrease mortality and morbidity, reduces the burden, and improves the quality of life as well $[8,10]$. Occupational therapists play an essential role in this team by helping individuals to resume independence in their activities. The interventions in these patients mainly focus on self-care and exercise training, activity modification, and energy conservation strategies [11]. Occupational therapists can also apply theories and frameworks of their profession to guide their practice in this setting.

The Ecology of Humane Performance (EHP) was developed as a practical framework by Winnie Dunn and colleagues at the University of Kansas Medical Center, and its conceptual emphasis was on the role of a person's context on his or her task performance [12]. For occupational therapists, EHP can be used as a framework to understand the complex transactions between the components involved in the formation of performance.

Four main constructs form the theoretical assumptions of the EHP: person, tasks, context, and personalcontext-task transaction [13]. In this framework, a person is composed of unique sensorimotor, cognitive, and psychosocial skills and abilities. Context is an interdependent condition that constitutes a person's surroundings and has temporal, physical, social, and cultural aspects. It can support or create barriers to participation based on the interaction with the person Tasks are a meaningful set of behaviors necessary to accomplish a goal. The construct of performance is the result of the interaction between the person, context, and task. According to EHP, five intervention strategies can be used to improve performance, each with a different target (i.e., person, task, or context) $[13,14]$ :

Establish/restore: This strategy focuses on the enhancement of the person's skills or abilities by teaching skills not previously learned or restoring lost skills due to an acquired disability.

Alter: In this strategy, the focus is on changing the context or environment in which a person performs.

Adapt/modify: In this intervention strategy, features of the context or task are changed or modified for successful performance.

Prevent: This strategy aims to minimize risks and thwarting the development of performance problems.

Create: This strategy aims to promote more adaptable or complex performance in one's natural context. In other words, the goal is to create contexts that support optimal performance [13-15].

Given the importance of the rehabilitation of patients with cardiovascular diseases and its effect in reducing the burden of care, the present study aimed to investigate the effectiveness of the EHP model in a patient with a history of cardiovascular disease.

\section{Case Report}

Mr. H, a 50-year-old male, was the father of a family. He was a retired teacher but was still teaching at a nonprofit school. He had a history of heart failure (grade 3 in NHYA). NHYA is one of the most commonly used classification systems for patients with heart failure. It classifies patients in one of four categories based on their limitations during physical activity; higher classes represent more functional limitations [16].

To assess the home environment and to involve the family, the intervention was provided at the client's home. Initially, the occupational therapist interviewed with $\mathrm{Mr}$. $\mathrm{H}$ and his family to determine his roles, responsibilities, and occupational performance challenges. According to our interview, he experienced major difficulties in some activities of daily living due to fatigue, fear of falling, and stress. Going to the toilet, bathing and 
Table 1. Summary of interventions based on EHP

\begin{tabular}{|c|c|}
\hline Strategies & Employed Strategy/Reported Outcomes \\
\hline Establish/Restore & $\begin{array}{l}\text { The therapist worked on increasing the endurance and muscle strength of the upper and lower extremities. } \\
\text { She also suggested some advice on how to have a better physical function and lower fatigue level according to } \\
\text { metabolic values (MET)1 for various activities. /These measures increased his endurance and independence } \\
\text { in ADLs. }\end{array}$ \\
\hline Alter & $\begin{array}{l}\text { Mr. H was retired but he continued to work because he was interested in being active. His job was stressful, so } \\
\text { the therapist and Mr. H discussed reducing his responsibilities and workloads. He changed his job from teaching } \\
\text { in a non-profit school to a secretor of a store. The new job was his offer. }\end{array}$ \\
\hline Adapt/Modify & $\begin{array}{l}\text { The therapist talked to the family about changing the type of toilet, putting a chair in the bathroom, and } \\
\text { increasing the height of the pray surface. These suggestions were made because of Mr. H's difficulties in sitting } \\
\text { and standing. / In this way he experienced lower levels of fatigue and fear of falling and more independence } \\
\text { during these occupations. }\end{array}$ \\
\hline Prevent & $\begin{array}{l}\text { The therapist taught some breathing exercises to reduce the risk of secondary respiratory problems and } \\
\text { increase cardiovascular capacity. }\end{array}$ \\
\hline Create & $\begin{array}{l}\text { The therapist helped Mr. } \mathrm{H} \text { to plan a weekly routine program for aerobic exercises at a club, as well as walking in } \\
\text { the park with his friends. She also referred him to a nutritionist and suggested him to increase the consumption } \\
\text { of fruits and vegetables in his diet. /These changed his lifestyle and improved his physical capacity and social } \\
\text { participation. }\end{array}$ \\
\hline
\end{tabular}

praying were among the activities in which he reported the highest level of dependence and the lowest sense of safety. So, he reported these actions as his priorities for occupational therapy intervention [17].

In the beginning, the researcher explained the process of the study and then the participant filled a written informed consent. We used the COPM as a tool to structure the interview session and to identify the participant's occupational issues and also as the outcome measure. COPM is a valid tool, especially in client-centered rehabilitation, and is commonly used to identify the client's occupational goals. It evaluates the performance and satisfaction of performance in areas of self-care, productivity, and leisure is scored on a 10-point Likert scale $[17,18]$.

An occupational therapist, in close collaboration with the client and his family, held the intervention twice a week. the intervention mainly included physical exercises aimed at enhancing the client's abilities as well as counseling him and his family about lifestyle changes and environmental adaptations. Table 1 summarizes the main actions based on EHP intervention strategies.

After approximately a six-month intervention period and based on the COPM scale, the 'performance' score increased from 5.3 to 8 and 'satisfaction' improved from 4.6 to 8.6 points. These improvements are clinically significant [17]. Mr. H also reported more independence and safety in most activities of daily living, especially on the three addressed occupations. He stated lower fatigue and helplessness during a day. At the six-month followup, the improvements were maintained and only the 'satisfaction' score reduced 1 point.

\section{Discussion}

Cardiovascular disease can result in significant difficulties in performing activities of daily living. It impairs functionality, restricts the routine activities, and makes it difficult for the patient to fulfill his or her roles; all consequently reduce the quality of life of the patient and his or her family $[8,19]$.

The cardiac rehabilitation aims to provide the best physical, mental, and psychosocial conditions for patients through a combination of exercise, consultation, education, and psychological support and the ultimate goal is to preserve or resume optimal functioning in the community $[8,10]$. Achieving this goal requires a holistic view of a person, his or her roles and tasks, as well as context or environment. The use of occupational therapy models can provide this comprehensive view. As mentioned earlier, we did not find a study that examined the effect of occupational therapy models in patients with cardiovascular diseases. This study was conducted to investigate the effectiveness of the EHP framework on the performance of daily occupations and satisfaction of the performance in a client with a history of cardiovascular disease. To the best of our knowledge, this research was 
the first study to evaluate EHP in patients with cardiovascular diseases. We found significant improvement in both performance and satisfaction of the performance. The patient also reported more independence and safety during his activities of daily livings and less fatigue and frustration.

EHP provides a comprehensive approach for evaluation and intervention because of its holistic view of the constructs involved in performance, including the person, task, and context. Besides, through its specific strategies, EHP reminds us that if it is not possible to improve or change one construct, other constructs can be addressed to improve performance. In this way, the environment and the role of environmental barriers and facilitators on the performance are considered more than routine occupational therapy interventions. A limitation to EHP is that intervention requires a collaborative therapeutic relationship with clients and their families, which can be time-consuming and increase the number of sessions.

There is little evidence with low quality about the effects of occupational therapy in heart patients and this area has received little attention in research [20, 21]. Although this little evidence suggests that cardiac rehabilitation, including occupational therapy, can be effective, it is necessary to conduct further studies with better methodology and a larger sample size [22, 23]. The major limitation of the present study is the low generalizability of the findings to a wider population due to its methodology.

\section{Conclusion}

Occupational therapists can facilitate the participation of clients in their daily routines through graded exercises and activities, adaptation or modification of the client's tasks and context, and education about energy expenditure and stress management $[20,21]$. While the occupational therapy can offer important contributions to the cardiac rehabilitation team, there is little evidence supporting this role and lack of research in this area may contribute to the absence of an occupational therapist in these settings.

This preliminary study showed that the application of the EHP model improved performance and satisfaction of performance in a patient with cardiovascular disease. It is suggested that in future studies, the effectiveness of occupational therapy interventions, as well as other occupational therapy models in these patients, be evaluated.

\section{Ethical Considerations}

\section{Compliance with ethical guidelines}

All ethical principles are considered in this article. The participants were informed about the purpose of the research and its implementation stages; they were also assured about the confidentiality of their information; moreover, they were free to leave the study whenever they wished, and if desired, the research results would be available to them.

\section{Funding}

This research did not receive any specific grant from funding agencies in the public, commercial, or not-forprofit sectors.

\section{Authors' contributions}

Conceptualization, supervision: Zeinab Fathipour-Azar; Methodology: Zeinab Fathipour-Azar; Investigation, writing - review \& editing: Bll authors ; Writing - original draft: Zeinab Fathipour-Azar.

\section{Conflict of interest}

The authors declared no conflict of interest.

\section{References}

[1] Gaziano T, Bitton A, Anand Sh, AbrahamsGessel Sh, Murphy A. Growing epidemic of coronary heart disease in low- and middleincome countries. Curr Probl Cardiol. 2010; 35(2):72-115. [DOI:10.1016/j.cpcardiol.2009.10.002] [PMID] [PMCID]

[2] Jahani A, Rejeh N, Heravi-Karimooi M, Hadavi A, Zayeri F, \& Khatooni A R. The relationship between spiritual health and quality of life in patients with coronary artery disease. Islam Life J. 2013; 1(2):17-21. [DOI:10.5812/islamlifestyle.8575]

[3] Seyam S, Heidarnia AR, sadat Tavafian S. Quality of life and factors related to it in cardiovascular patients after heart surgery. $\mathrm{J}$ Birjand Univ Med Sci. 2013; 19(6):33-41. http://journal.bums.ac.ir/ article-1-1227-en.html.

[4] Garcia S, Alosco M L, Spitznagel MB, Cohen R, Raz N, Sweet L, Oberle M. L. Cardiovascular fitness associated with cognitive performance in heart failure patients enrolled in cardiac rehabilitation. BMC Cardiovasc Disord. 2013; 13(1):29. [DOI:10.1186/1471 2261-13-29] [PMID] [PMCID]

[5] Yamada S, Shimizu Y, Suzuki M, \& Izumi T. Functional limitations predict the risk of rehospitalization among patients with chronic heart failure. Circ J. 2012; 76(7):1654-61. [DOI:10.1253/circj.CJ11-1178] [PMID] 
[6] LaPier TK. Utility of the late life function and disability instrumen as an outcome measure in patients participating in outpatient cardiac rehabilitation: A preliminary study. Physiother Can. 2012; 64(1):5362. [DOI:10.3138/ptc.2010-30] [PMID] [PMCID]

[7] Shojaei F. Quality of life in patients with heart failure. Hayat. 2008; 14(2):5-13. https://hayat.tums.ac.ir/article-1-142-en.html

[8] Anderson L, Sharp GA, Norton RJ, Dalal H, Dean SG, Jolly K, et al. Home-based versus centre-based cardiac rehabilitation. Cochrane Database Syst Rev. 2017; 2017(6):CD007130. [DOI:10.1002/14651858.CD007130.pub4] [PMCID]

[9] Dalal H, Doherty P, Taylor R. Cardiac rehabilitation. BMJ. 2015; 351:h5000. [DOI:10.1136/bmj.h5000] [PMID] [PMCID]

[10] Cowie A, Buckley J, Doherty P, Furze G, Hayward J, Hinton J, et al. Standards and core components for cardiovascular disease prevention and rehabilitation. BMJ. 2019; 105:510-5. [DOI:10.1136/ heartjnl-2018-314206] [PMID] [PMCID]

[11] Wilde C, Hall J. Occupational therapy in cardiac rehabilitation: Resumption of daily life activities. Phys Med Rehabil Clin N Am. 1995; 6(2):349-72. [DOI:10.1016/S1047-9651(18)30470-4]

[12] Dunn W, Brown C, \& McGuigan A. The ecology of human performance: A framework for considering the effect of context. Am J Occup Ther. 1994; 48(7), 595-607. [DOI:10.5014/ajot.48.7.595] [PMID]

[13] Cole M, Tufano R. Applied theories in occupational therapy: A practical approach. $2^{\text {nd }}$ edition. Thorofare, NJ: Slack Incorporated; 2019.

[14] Silvestri J. Effects of chronic shoulder pain on quality of life and occupational engagement in the population with chronic spinal cord injury: Preparing for the best outcomes with occupational therap. Disabil Rehabil. 2017; 39(1):82-90. [DOI:10.3109/09638288.2016 .1140829] [PMID]

[15] Kramer P, Hinojosa J, \& Royeen C. B.. Perspectives in human occupation: Participation in life. Philadelphia: Lippincott Williams \& Wilkins; 2003

[16] Sinescu C, Axente L. Heart failure -- concepts and significance. Birth of a prognostic model. J Med Life. 2010; 3(4):421-9. [PMCD] [PMCID]

[17] Law M, Baptiste S, Mc.Coll M, Opzoomer A, Polatajko H Pollock N. The Canadian Occupational Therapy Measure: An outcome measure for occupational therapy. Can J Occup Ther. 1990; 57(2):82-7. [DOI:10.1177/000841749005700207] [PMID]

[18] Cup E, Reimer W, Thijssen M, Kuyk-Minis M. Reliability and validity of the Canadian Occupational Performance Measure in stroke patients. Clin Rehabil. 2003; 17(4):402-9. [DOI:10.1191/0269215503cr635oa] [PMID]

[19] Fathipour-Azar Z, Akbarfahimi M, Vasaghi-Gharamaleki B Naderi N. Evaluation of activities of daily living instruments in cardiac patients: Narrative review. J Mod Rehabil. 2016; 10(3):13943. https://jmr.tums.ac.ir/index.php/jmr/article/view/43

[20] Wells JK. Occupational therapy and physical therapy in clients after open heart surgery: A review of current literature. IJOT. 2007; 38(3). https://www.researchgate.net/publication/323793321_

[21] Cherney A, Gregoire-Norrie Sh. Cardiac rehabilitation: A course for occupational therapy students. Occupational Therapy Capstones: University of North Dakota (UND); 2008. https://commons.und. edu/cgi/viewcontent.cgi? article $=1039 \&$ context $=$ ot-grad
[22] Long L, Mordi IR, Bridges C, Sagar VA, Davies EJ, Coats AJS. Exercise-based cardiac rehabilitation for adults with heart failure. Cochrane Database Syst Rev. 2019; 1(1):CD003331. [DOI:10.1002/14651858.CD003331.pub5] [PMID] [PMCID]

[23] Anderson L, Taylor RS. Cardiac rehabilitation for people with heart disease: An overview of Cochrane systematic reviews. Cochrane Database Syst Rev. 2014; 2014(12):CD011273. [DOI:10.1002/14651858.CD011273.pub2] [PMID] [PMCID] 
استفاده از مدل اكولوزى عملكرد انسان در كاردرمانى بيمارى قلبى: يكى مطالعه موردى

$$
\text { زينب فتحى يور آذر "(-) ، مهناز حجازى شيرمرد' }
$$

ا. دانشجوى دكترى تخصصى كاردرمانى، دانشكاه علوم يزشكى ايران، تهران، ايران.

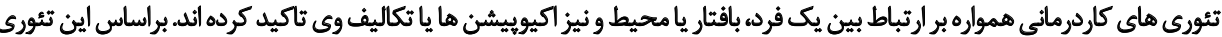

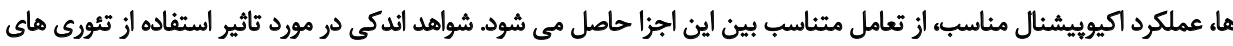

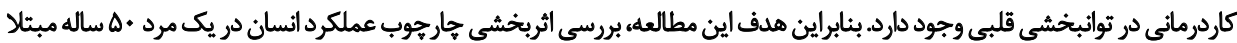

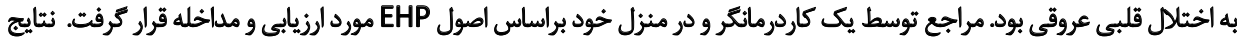

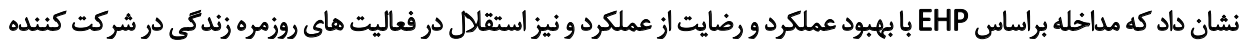

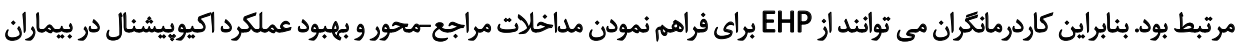

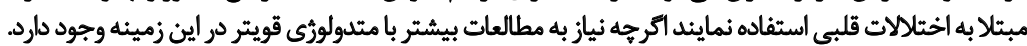

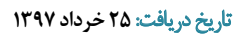

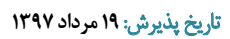

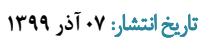

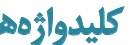
اكولوزي عملكرد انسان؛ كاردرماني؛ بيمارى قلبي 